\title{
PD-1 mRNA expression in peripheral blood cells and its modulation characteristics in cancer patients
}

\author{
Wei Wang ${ }^{1}$, Ge Shen ${ }^{1}$, Shikai Wu ${ }^{1}$, Shiping Song ${ }^{1}$, Yanli Ni $^{1}$, Zhuoyao Suo ${ }^{1}$, \\ Xiangying Meng ${ }^{1}$, Dan Li ${ }^{1}$, Lin Zhou ${ }^{1}$, Rimin Hao ${ }^{1}$, Yaowei Zhao ${ }^{1}$, Li Bai ${ }^{1}$, Lili Hou ${ }^{1}$, \\ Bing Liu ${ }^{1}$ and Guangxian Liu ${ }^{1}$ \\ ${ }^{1}$ Cancer Therapy Center, Affiliated Hospital of The Academy of Military Medical Sciences, Beijing 100071, China \\ Correspondence to: Guangxian Liv, email: liugx270@hotmail.com \\ Bing Liu, email: bingliu17@yahoo.com \\ Keywords: PD-1, peripheral immune cells, immunomodulation, radiation therapy, cancer \\ Received: June 15, $2016 \quad$ Accepted: January 16, $2017 \quad$ Published: February 02, 2017 \\ Copyright: Wang et al. This is an open-access article distributed under the terms of the Creative Commons Attribution License 3.0 \\ (CC BY 3.0), which permits unrestricted use, distribution, and reproduction in any medium, provided the original author and source \\ are credited.
}

\section{ABSTRACT}

Immune checkpoint inhibitors that block the PD-1/PD-L1 signaling pathway have been used to treat a wide variety of cancers. Although results have been promising, significant inter-individual and inter-tumor variability has been observed. It is believed that better clinical outcome could be achieved if the treatment was individually designed based on the functional status of the PD-1/PD-L1 signaling and the cellular immunity. In this study, we analyzed the mRNA expression of PD-1 and other immunomodulatory genes in peripheral blood from cancer patients, and immunomodulatory gene expression during radiotherapy and immunomodulation therapy with cytokines. Our results show that the PD-1 mRNA expression is significantly increased in peripheral blood in cancer patients. Anti-cancer treatments can significantly modulate the PD-1 expression, but this is largely dependent on the initial immune status. Moreover, the PD-1 expression on peripheral lymphocytes can be immunoactivation-derived. These results suggest that the regulation and expression pattern of PD-1/PD-L1 signal is complicated which will influence the effect of blockade of the PD-1/PD-L1 signaling pathway for cancer treatment. Through combined analysis of PD-1, CTLA-4, and other immune markers in peripheral blood, we may accurately evaluate the functional status of PD-1/PD-L1 signaling and cellular immunity, thereby providing clues for guiding anti-PD-1 or antiPD-L1 treatment.

\section{INTRODUCTION}

Programmed death-1(PD-1,CD279), a member of the immunoglobulin superfamily, is an immune checkpoint receptor that is expressed on the surface of peripheral $\mathrm{T}$ cells, B cells, natural killer T (NKT) cells, dendritic cells(DC), and some monocytes. Upon binding to its ligands, programmed death-1 receptor ligand-1 (PD-L1) or -2 (PD-L2), the PD-1 engagement leads to inhibition of cell growth and cytokine secretion, normally serving as a feedback inhibitory mechanism of the immune system [16]. However, this mechanism has been linked to immune tolerance and therefore provides a possible mechanism of escaping immune surveillance when tumor cells become capable of expressing PD-L1 [7, 8].
Recently, blockade of the immune checkpoints using monoclonal antibodies against cytotoxic T-lymphocyte antigen-4 (CTLA-4), PD-1, and PD-L1, has shown striking clinical results in cancer patients [9-13]. Pembrolizumab is the first monoclonal antibody targeting PD-1 [11], which has been used in advanced melanoma patients [12, 14]. Nivolumab is another fully humanized monoclonal antibody against PD-1; it has been used in clinical trials to treat melanoma, non-small cell lung cancer, and renal cell carcinoma [15]. Although preliminary results from these clinical trials have been striking, they have not yet met the expectation for the potency of the new treatment strategy. In addition, a significant interindividual and inter-tumor variability in response to these antibodies has been observed [16]. 
It is believed that better clinical outcomes could be achieved if the treatment is individually designed based on the functional status of the PD-1/PD-L1 signaling and the cellular immunity [17-18]. Early studies suggested that measurement of PD-1 on tumor infiltrated lymphocytes (TILs) and PD-L1 expression on tumor cells after surgery or biopsy might be advisable [19-22]. However, later studies indicated that PD-1 expression on peripheral blood leukocytes may provide a more useful and practical indicator of cancer progression, and may assist in identifying patients likely to respond to PD-1/ PD-L1 blockade [23, 24]. However, since the relationship between the clinical response to PD-1 antibodies and the immune status is complicated, monitoring PD-1 expression on tumor infiltrated lymphocytes as well as PDL1 on tumor cells is clinically impractical and insufficient for most patients. A more reliable and practical protocol for evaluating the functional characteristics of the PD-1 signaling pathway and the cellular immunity is urgently needed.

In this study, we have analyzed PD-1 mRNA expression in peripheral blood from cancer patients, and evaluated its modulation during clinical treatments with radiotherapy and immunomodulation therapy with cytokines. Our results show that PD-1 mRNA expression is increased in peripheral blood from cancer patients, and can be modulated by clinical procedures. Moreover, the PD-1 expression on peripheral lymphocytes can be immunoactivation-derived. Our data indicate that through combined analysis of PD-1, CTLA-4, CD25, CD28, Foxp3, TGF- $\beta$ and IL-10 expression and the lymphocyte subpopulations in peripheral blood, we could accurately evaluate the functional status of cellular immunity and PD-1/PD-L1 signaling pathway, which could provide clues for guiding cancer treatment using anti-PD-1 antibodies.

\section{RESULTS}

\section{PD-1 and CTLA-4 mRNA expression in healthy adults and cancer patients}

Ten healthy adults and 45 cancer patients were analyzed for gene expression of PD-1, CTLA-4, CD25, CD28, IL-10, TGF- $\beta$ and Foxp3 in peripheral blood. As shown in Figure 1A and Supplementary Tables 1 and 2, expression of PD-1 and CTLA-4 in cancer patients was significantly increased compared to that in healthy adults( $\mathrm{p}=0.04)$. Specifically, expression of PD-1 in $71 \%$ $(32 / 45)$ and CTLA-4 in 87\% (39/45) cancer patients was higher than in all ten healthy adults. Next, we analyzed PD-1 and CTLA-4 mRNA levels in mononuclear cells (PBMC) isolated from peripheral blood. As shown in Figure 1B, even though the gene expression of PD-1 and CTLA-4 in PBMC of cancer patients was increased, it did not reach a statistical significance; this will need to be further investigated with a larger cohort.

\section{Modulation of PD-1 and CTLA-4 mRNA expression during cancer treatment}

Cellular immunity of 45 cancer patients, including 25 cases received immunomodulation therapy and 20 cases received radiotherapy, was monitored by flow cytometry. The proportion of T cells (70.05-71.29\%), B cells (10.21-7.53\%), NK cells(19.85-20.64\%), Treg cells(3.32-3.74\%), CD3 ${ }^{+} \mathrm{CD}^{+} \mathrm{CD} 28-$ cells(14.32-15.57\%), and $\mathrm{CD}^{+} \mathrm{CD}^{+} \mathrm{CD}^{+} 8^{+}$cells(15.18-15.26\%) showed no significant differences between before and after treatment (Supplementary Table 3).

Interestingly, the PD-1 mRNA expression declined in 12 patients $(48 \%)$ and increased in $13(52 \%)$ patients in the cohort with immunomodulation therapy. CTLA-

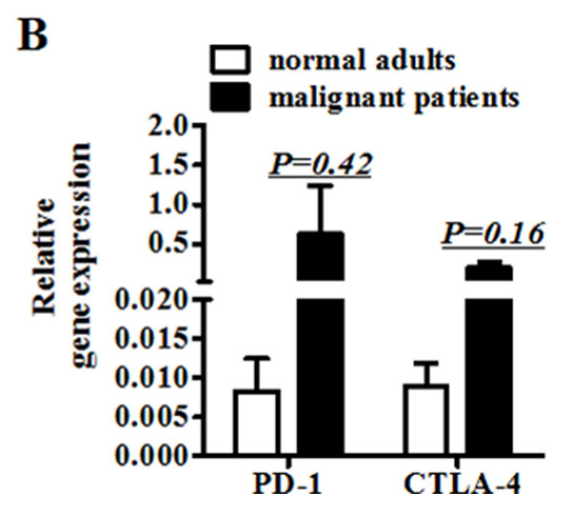

Figure 1: The gene expression of PD-1 and CTLA-4 in peripheral blood. A. The mRNA expression of PD-1 and CTLA-4 in peripheral blood from ten normal adults and 45 patients. B. The mRNA expression of PD-1 and CTLA-4 in mononuclear cells (PBMC) separated from peripheral blood of normal adults and patients. (A) Significance of the data were calculated and denoted as $*, p<0.05$. (B) The data is representative of two independent experiments and have not significance. 
4 mRNA expression decreased in 9 patients (36\%) and increased in 16 patients $(64 \%)$ (Figure $2 \mathrm{~A})$. The up- and down-modulation of PD-1 and CTLA-4 mRNA expression in the patients largely depended on the initial mRNA levels. If the initial expression was increased, it would be decreased after therapy, and vice versa.

In the cohort with radiotherapy, PD-1 mRNA expression declined in 15 patients $(75 \%)$, and increased in $5(25 \%)$ patients. CTLA-4 mRNA levels decreased in 15 patients $(75 \%)$ and increased in 5 patients $(25 \%)$ (Figure 2B). The up- and down-modulation of PD-1 and CTLA-4 mRNA expression in the patients also largely depended on the initial expression levels. Notably, there was a significant difference in the mRNA levels of PD-1 and CTLA-4 between radiotherapy and immunomodulation therapy. When the mRNA levels of PD-1 and CTLA4 after treatment minus that before for each patient, it was found that the radiation cohort had much decreased mRNA levels of PD-1 and CTLA-4 than that in the immunomodulation cohort, with significant difference for CTLA-4 $(p=0.006)$ but not for PD-1 $(p=0.24)$, see Figure 3A. Comparison of the influence of cytokines or cytokine combination on the PD-1 and CTLA-4 mRNA levels in PBMC from normal adults and cancer patients revealed that the PD-1 and CTLA-4 expression increased in most cancer patients prior to cytokine treatment, and was hardly modulated after the treatment (Figure 3B), indicating the intrinsic inhibition of the immune function by tumors. As there were several types of cancer in the immunomodulation cohort, we also compared the PD-1 and CTLA-4 mRNA expression between the 7 lung cancer patients and 18 other malignancies. The results showed that there was no significant difference between the two groups in PD-1 and CTLA-4 mRNA expression as well as in lymphocyte counts (data not shown).

\section{Correlation of PD-1 mRNA expression with other immunosuppressive genes}

We have also measured mRNA levels of CD25, CD28, Foxp3, TGF- $\beta$ and IL-10 during the treatments (Figure 2). The modulation of these genes by the treatments also largely depended on their initial levels. Interestingly, much larger bidirectional regulatory effect among these genes was found in the immunomodulation therapy cohort than in the radiation cohort. Particularly, in the cohort with immunomodulation therapy, PD-1 mRNA expression highly correlated with CTLA-4 (96\%), followed by CD28 (80\%), Foxp3 (80\%), CD25 (76\%) and IL-10 (76\%), and negatively correlated with TGF- $\beta$ (40\%), CD25 (24\%), IL-10 (24\%), CD28 (20\%), and Foxp3 $(20 \%)$ (Figure 4A). However, in the cohort with radiation therapy, there was no significant reverse correlation among these signals. Instead, PD-1 mRNA expression correlated with CTLA-4 (85\%), CD25 (90\%), CD28 (85\%), Foxp3 $(90 \%)$, TGF- $\beta(85 \%)$ and IL-10 (95\%) expression, and reversely correlated with all the other molecules $<15 \%$ (Figure 4B). These results revealed that the modulation mechanism of these functional molecules was different between the two kinds of therapy.

The expression of IFN- $\gamma$ in peripheral blood was also monitored, but was undetectable by the RT-PCR method. In substitution, we monitored IFN- $\gamma$ expression in blood CD4 and CD8 cells by flow cytometry. We found that $\mathrm{CD}^{+} \mathrm{CD} 4^{+} \mathrm{IFN}-\gamma^{+}$and $\mathrm{CD}^{+} \mathrm{CD} 8^{+} \mathrm{IFN}-\gamma^{+}$ subpopulations were frequently modulated during the treatments, but there was no significant correlation between IFN $-\gamma^{+} \mathrm{CD} 4$ or $\mathrm{IFN}-\gamma^{+} \mathrm{CD} 8$ cell count and peripheral PD-1 expression(data not shown). Further investigation is needed with a large cohort.

\section{DISCUSSION}

In the present study, we have analyzed PD-1 mRNA expression in peripheral blood leukocytes as well as mRNA expression of several key immunoregulatory genes before and after cancer treatments. Gene expression of PD-1 as well as CTLA-4, CD25, CD28, Foxp3, TGF- $\beta$ and IL-10 was increased in most cancer patients compared to that in healthy adults (see Figure 1, Supplementary Tables 1 and 2). No significant difference in PD-1 and CTLA-4 mRNA expression and in lymphocyte counts were observed between 7 lung cancer patients and 18 other malignancies in the immunomodulation therapy cohort, suggesting dysregulated cellular immunity in cancer patients. In vitro data showed that these signals in peripheral immune cells from patients were hardly modulated in 24 hours by cytokines or their combination, with minimal fluctuation of PD-1 and the other signals, obviously different from that in normal immune cells, indicating functional abnormality or blockage of the immune cells.

Expression of PD-1, CTLA-4, CD25, CD28, Foxp3, TGF- $\beta$ and IL-10 could be easily modulated with a broad range of clinical therapeutic procedures. Previous studies have shown that some treatments, such as hypomethylating agents (HMAs), 5-azacytidine and 5-aza-2' deoxycytidine, can induce immune reaction alterations $[25,26]$. Yang et al reported that, in a cohort of patients with MDS, CMML, AML treated with epigenetic therapy, PD-L1, PD-L2, PD-1 and CTLA4 expression was up-regulated and patients resistant to therapy had higher PD-1 and CTLA4 expression compared to patients who responded to therapy. Treatment of leukemia cells with decitabine resulted in a dose dependent up-regulation of the above genes. It is believed that many treatments or drugs can affect functional status of these signals, with special significance in cancer immunotherapy [27]. In this study, we observed a rapid modulation of PD-1 mRNA expression after radiation and immunomodulation therapy. Interestingly, the response of PD-1 mRNA expression upon clinical treatment was observed in each of the 
A Immunomodulatory therapy
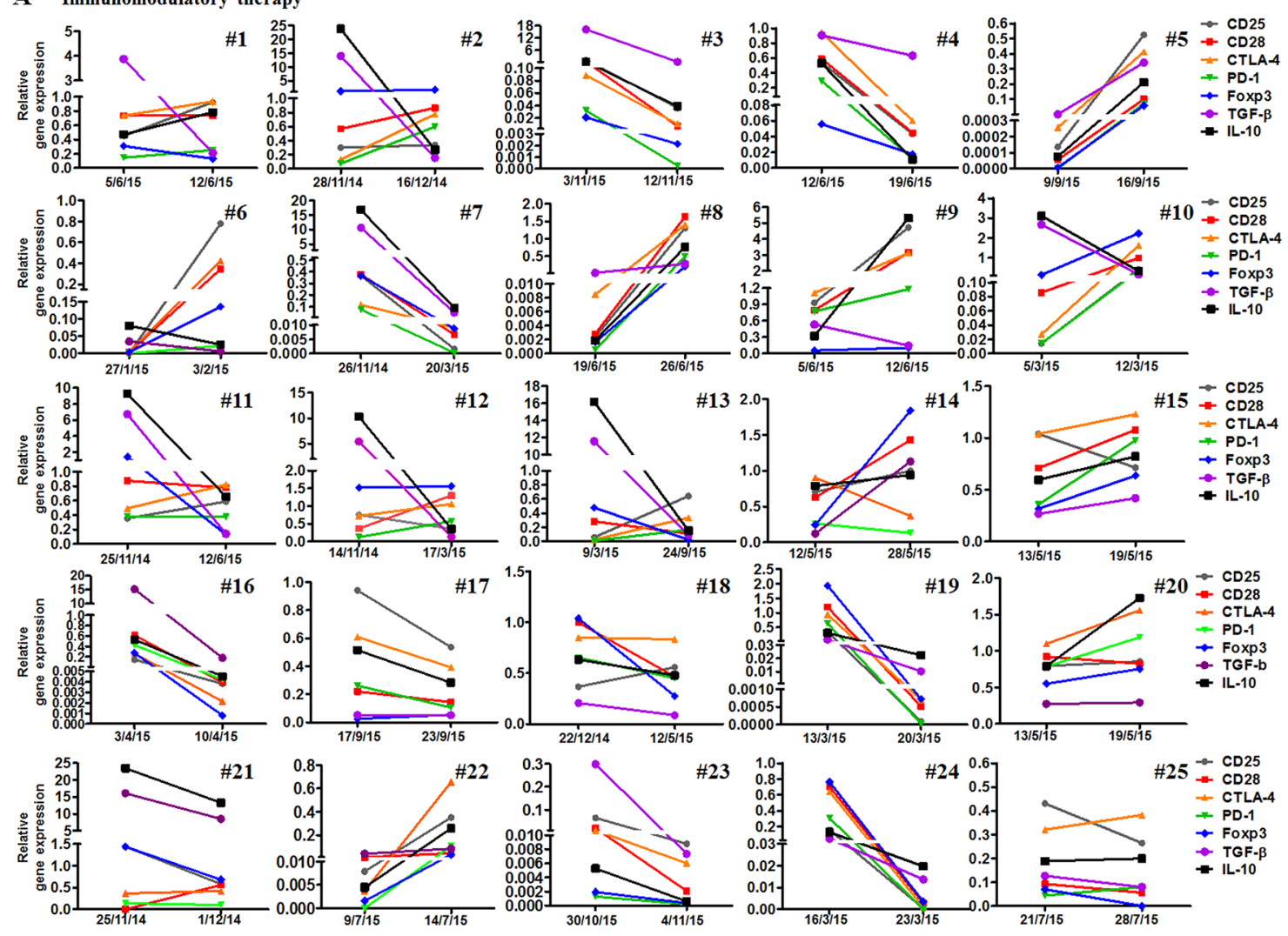

Date $(d / m / y)$
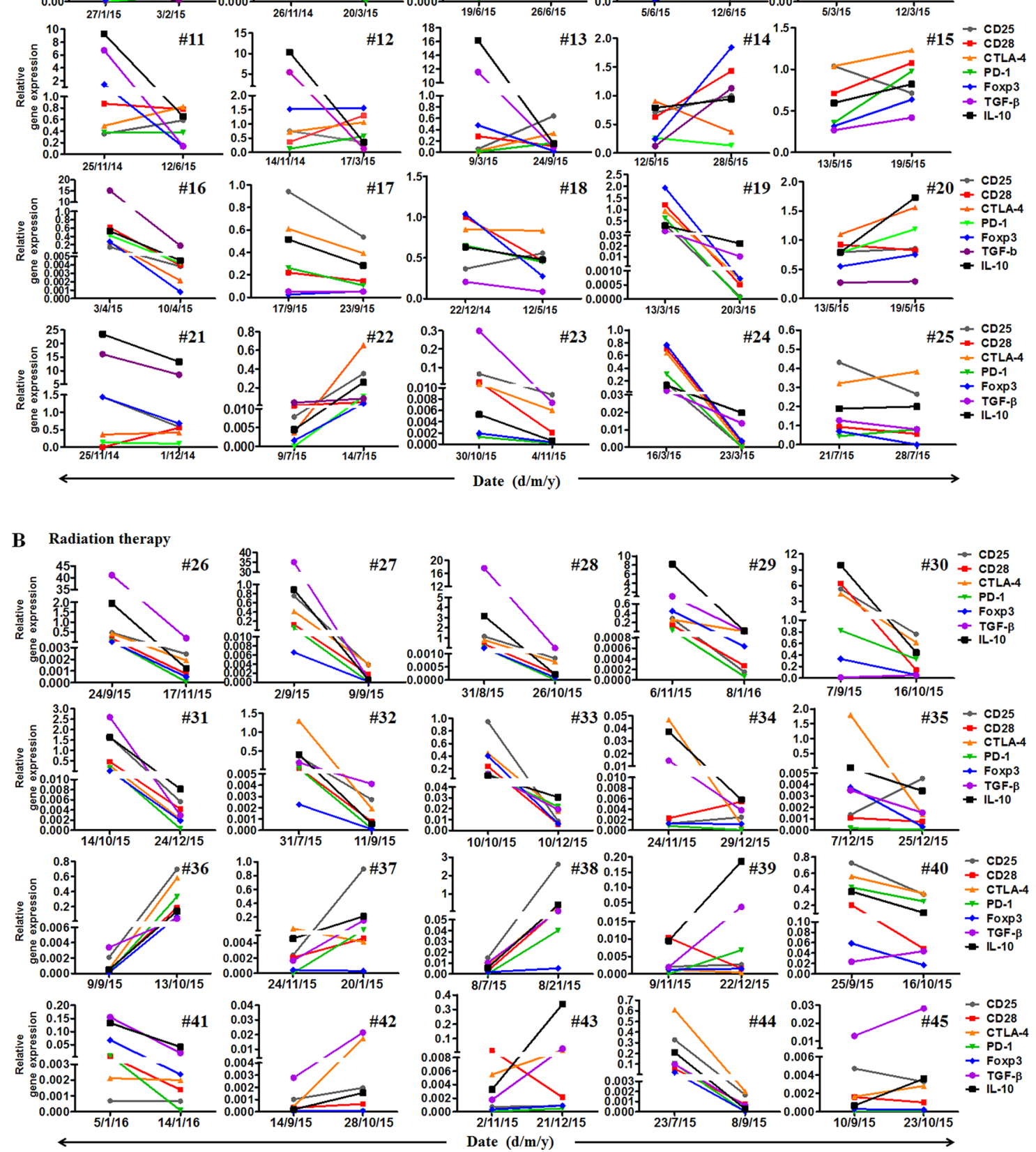

$25 / 9 / 15 \quad 16 / 10 / 15$

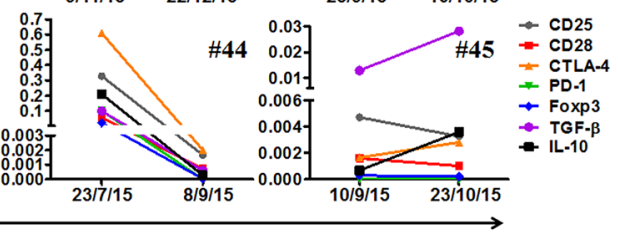

Figure 2: Monitoring mRNA expressions of seven immunoregulatory molecules including CD25, CD28, CTLA4, PD-1, Foxp3, TGF- $\boldsymbol{\beta}$ and IL-10. A. The mRNA expression of the seven molecules in 25 malignant patients before and after immunomodulation therapy. B. The expression of the seven molecules in 20 malignant patients before, after and one month (IMRT) or two months (CyberKnife) after radiotherapy. 

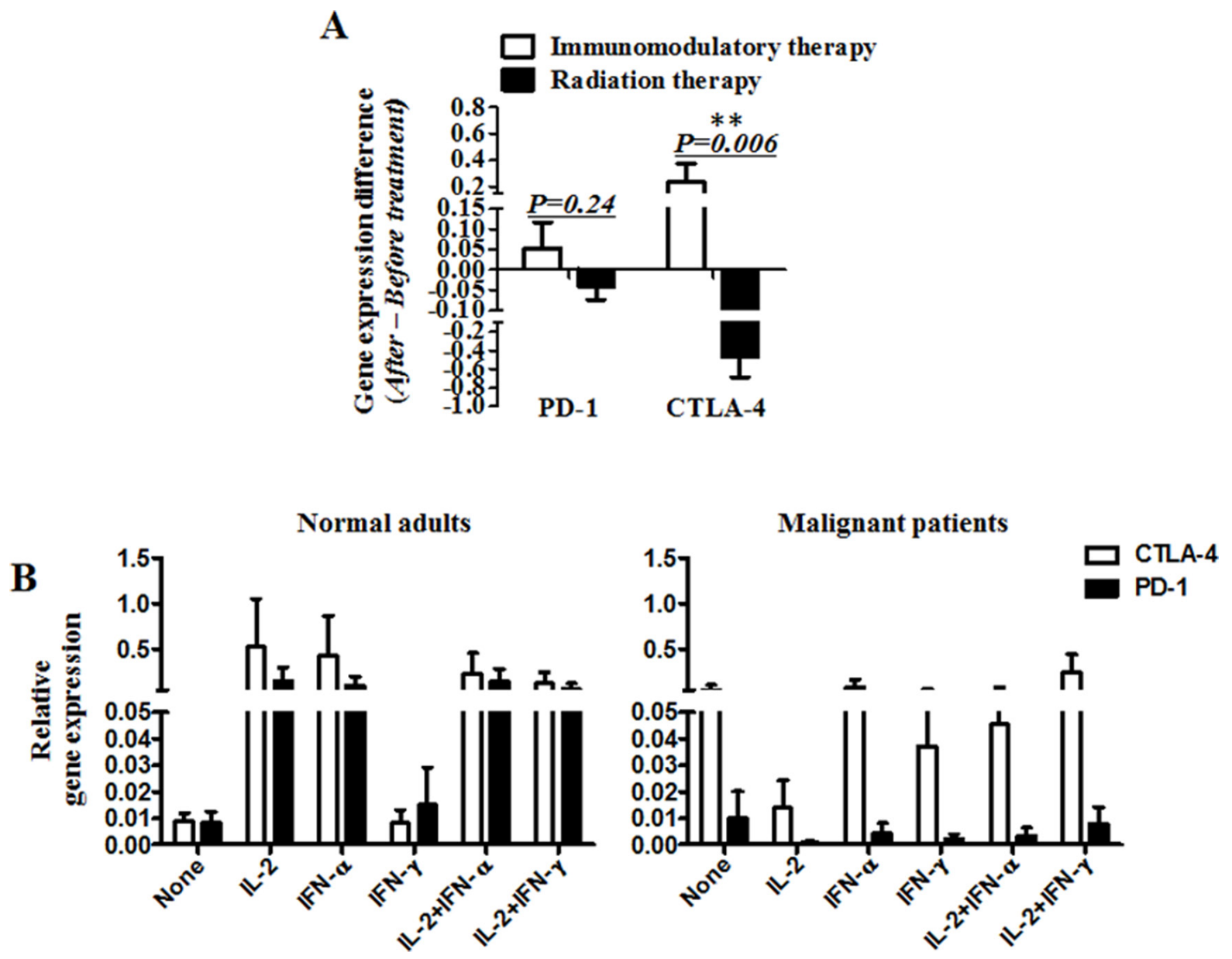

Figure 3: The mRNA levels of PD-1 and CTLA-4 in vivo and in vitro. A. The mRNA levels of PD-1 and CTLA-4 after treatment minus that before for each patient. B. The mRNA expression of PD-1 and CTLA-4 in peripheral blood mononuclear cells (PBMC) from normal adults or malignant patients, stimulated by cytokines (IL-2, IFN- $\alpha$ and IFN- $\gamma$ ) or cytokine combination (IL-2+IFN- $\alpha$ and IL$2+\mathrm{IFN}-\gamma$ ). (A) Significance of the data were calculated and denoted as $* *, p<0.01$. (B) The data is representative of two independent experiments and have not significance.
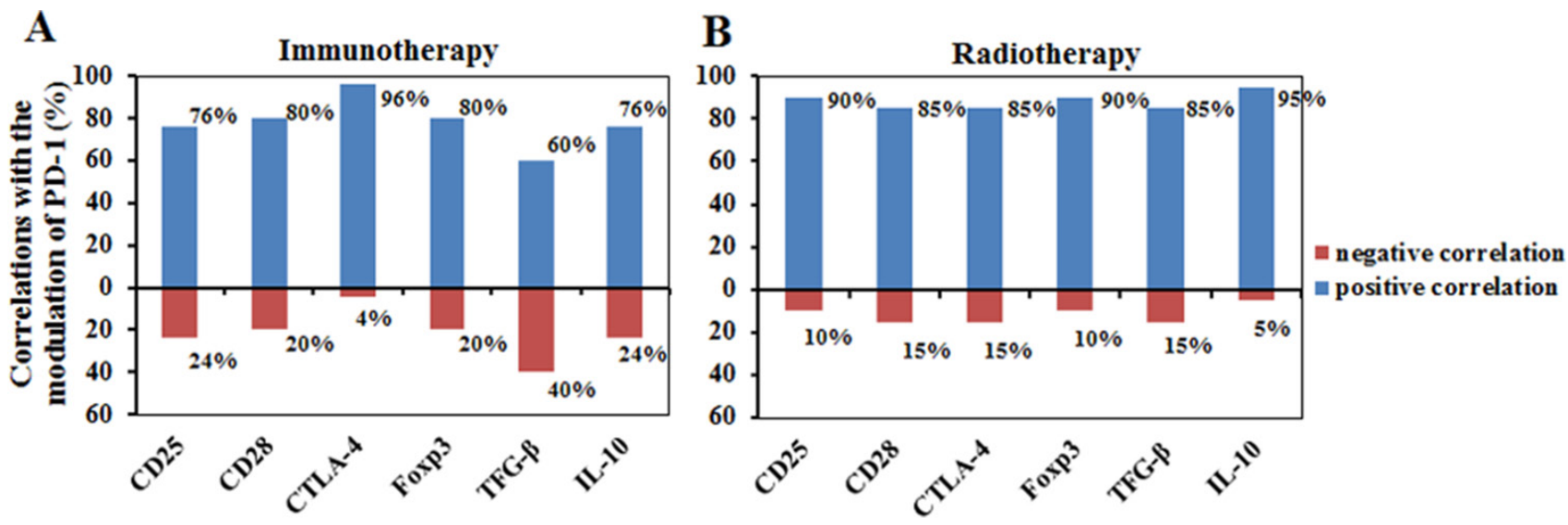

Figure 4: The correlation of PD-1 with six other functional immune molecules including CD25, CD28, CTLA-4, Foxp3, TGF- $\beta$ and IL-10 after immunomodulation therapy A. or radiotherapy B. Blue column, positive correlation; Red columns, negative correlation. 
clinical interventions and largely depended on the initial expression level. In contrast, radiation therapy had much larger amplitude of the response. The same phenomenon was also observed in the responses of CD25, CD28, CTLA-4, TGF- $\beta$ and IL-10, which seems to be derived from both immunoactivation and stimulation by the two kinds of therapy, as either of the two actions could not entirely explain the phenomenon and the data (see Figure 2). Further dynamic observation showed that the PD-1 mRNA expression by RT-PCR, the PD-1 expression on lymphocytes by cytometry and the IFN- $\gamma$ expression in CD4 and CD8 by cytometry were not synchronous (data not shown), which could be influenced by their different expression time spans.

To date, most studies have focused on PD-1 expression on TILs and PD-L1 expression on tumor cells. The results have shown that upregulation of PD-1 on TILs or PD-L1 on tumor cells was associated with immunotolerance, exhaustion of $\mathrm{T}$ cells, and poor prognosis [28-34]. Several studies have found that persistent expression of PD-1 by $\mathrm{T}$ cells is highly indicative of an exhausted phenotype noted by a decrease in effector function and linked to poor prognosis and tumor recurrence [35-37]. Data from this study showed that PD-1 and CTLA-4 up-regulation in the cohort of immunomodulation therapy had positive correlation with CD25 and CD28, but negative correlation with TGF- $\beta$, and no correlation with Foxp3. These results indicate that the increased expression of PD-1 upon treatment could be caused by immunoactivation, different from that in TILs, which largely represent the PD-1 up-modulation induced by tumor, as reported previously [38-45].

The most impressive result was the correlation of PD-1 mRNA expression with that of other immunoregulatory molecules and the difference in immunomodulation during different therapies. Increased PD-1 expression could be cancer-derived [30-36] or immunoactivation-derived, but not specific. We found that the increased PD-1 mRNA expression was companied by modulation of other immune molecules, but with different patterns among individuals or treatments (Figure 4). Interestingly, there was positive or negative correlation between expression of these molecules in the cohort of immunomodulation therapy, but only minimal negative correlation could be found in the cohort of radiotherapy, with special interests coming from the modulation of TGF- $\beta$ and IL-10. In the cohort of immunomodulation therapy, there was high correlation between PD-1 and CTLA-4, CD25 and PD-1, followed by Foxp3; CD28 and Foxp3, TGF- $\beta$ and IL-10, followed by Foxp3. There was reverse correlation ( $20 \%-40 \%$ cases) between PD- 1 and TGF- $\beta$, CTLA- 4 and TGF- $\beta$, CD 25 and TGF- $\beta$, CD2 8 and TGF- $\beta$, followed by IL-10; Foxp 3 and CTLA-4 followed by IL-10; IL-10 and CTLA-4. However, in the cohort with radiotherapy, the increase of $\mathrm{PD}-1 \mathrm{mRNA}$ expression was companied by all six genes, but there was only minimal reverse correlation $(<15 \%$ cases $)$ between CTLA-4 and CD25, CD28 and IL-10, Foxp3 and CD28, TGF- $\beta$ and CD28, IL-10 and CD28. When contrasting the mRNA levels of PD-1 and CTLA-4 between radiotherapy and immunomodulation therapy, it was found that they were mostly up-modulated after immunomodulation therapy and down-modulated after radiotherapy. These results indicate that the two types of therapy mediate immune responses through different immunoregulatory mechanisms, and that the immunomodulation therapy has much higher immunoregulatory activity. We did not observe correlation between PD-1 and Foxp3, though PD-1 and CTLA-4 upmodulation was often associated with CD25 up-regulation, suggesting their immunoactivation-derived property, without regulatory $\mathrm{T}$ cell induction $[29,31]$. In addition, in comparison with immunomodulation therapy, radiation therapy was associated with increased TGF- $\beta$ expression. The induced TGF- $\beta$ might be immune-cell-derived or radiation-damage-induced [46-48], but regardless of its origin, the increased TGF- $\beta$ expression likely affects the antitumor immunity, thus indicating the necessity of further immunomodulation therapy immediately after radiation therapy for some patients. In future, we will investigate the effect of such immunomodulation on antitumor immunity and function of the PD-1/PD-L1 signaling pathway.

In summary, our results demonstrate modulation of peripheral blood PD-1 mRNA levels after antitumor treatment. Our data show that the PD-1 gene expression is increased in peripheral blood in cancer patients, and can be modulated by clinical interventions. Cytokine immunomodulation therapy and ionizing irradiation have different immunomodulation effect; the immunomodulation therapy is associated with higher immunoreactivity and cytokine-induced PD-1 expression. Moreover, the PD-1 expression on peripheral lymphocytes can be immunoactivation-derived, different from that in TILs. Together, our data suggest that through combined analysis of PD-1, CTLA-4, CD25, CD28, Foxp3, TGF- 3 and IL-10 in peripheral blood, and the lymphocyte subpopulations, we may accurately evaluate the functional status of cellular immunity, thus providing clues for guiding blockade of PD-1/PD-L1 signaling pathway for cancer treatment.

\section{MATERIALS AND METHODS}

\section{Patients and blood sample preparation}

Blood samples were obtained from patients with lung $(\mathrm{n}=27)$, renal $(\mathrm{n}=2)$, breast $(\mathrm{n}=5)$, gastrointestinal $(\mathrm{n}=4)$, and other malignancies $(\mathrm{n}=7)$ prior to or after radiotherapy and immunomodulation therapy with cytokines. Blood samples from healthy adults were freshly obtained from the blood bank in our hospital. Written consents were obtained from all patients. The protocol was 
approved by the Human Ethics Committee of the Affiliated Hospital of the Academy of Military Medical Sciences, Beijing, China, and was conducted in accordance with the Declaration of Helsinki. Whole blood $(8 \mathrm{ml})$ was drawn into heparinized tubes for cytometry and RT-PCR analysis.

\section{Analysis of the cellular immunity}

For monitoring the cellular immunity, T cells, B cells, NK cells, Treg cells, and lymphocyte subpopulations were analyzed by a 4-color flow cytometry (EPICS XL, Beckman Coulter Inc., USA). Fluorescein isothiocyanate (FITC)-, PE-Cy5-, PerCP-, allophycocyanin (APC)-, or PE-Texas Red (ECD)-conjugated antibodies against CD3, CD4, CD8, CD56, CD19, CD25, CD28, HLADR, CD45RA, and CD45RO were purchased from Beckman Coulter Inc. Cells were labeled according to the manufacturer's protocols.

\section{Analysis of gene mRNA expression}

Expression of CD25, CD28, IL-10, TGF- $\beta$, Foxp3, CTLA-4, and PD-1 was analyzed by a real time RT-PCR (Beijing Mo Li Tai Bio-Technology Inc., Cat:201411). Briefly, lymphocytes were collected from peripheral blood of the patients by centrifugation at $400 \times \mathrm{g}$ for 5 minutes. The cells collected were then mixed with a red blood cell lysing solution (Bejing Dong Fang Hua Hui Biomedical Technology, Cat:21510) at 1:9 ratio and centrifuged Total RNA was isolated using a standard RNA isolation procedure according to the manufacturer (Life technologies, Cat: 15596-026). The RNA was then reversely transcribed into cDNA using a reverse transcription system (Promega, Cat: A5300). Real time PCR was performed using a 7500 real time PCR system (Applied Biosystems); $\beta$-actin was employed as the control gene.

\section{Immunomodulation therapy}

Immunomodulation therapy with cytokines was designed according to the cellular immunity analyzed by flow cytometry [17]. Briefly, IFN- $\alpha-1 b$ (Beijing Tri-Prime Gene Inc.), IL-2 (Beijing Shuanglu Phamacutical Inc. China) and Thymalfasin (Hainan Zhonghe Pharmaceutical CO. LTD) were used. The doses were $300 \mathrm{MU}$ of IFN- $\alpha$, 200 MU of IL-2 and 1mg of Thymalfasin for each injection. The modification was that, if the CD4/CD8 ratio was $<1,1.6 \mathrm{mg}$ of Thymalfasin was added at every other day for four to six weeks. In addition, the following prerequisites were needed for the patients to receive the therapy: the absolute neutrophil count $>0.3 \times 10^{9} / \mathrm{L}$ and platelet count $>70 \times 10^{9} / \mathrm{L}$, normal liver and renal function, at least two weeks after chemotherapy or operation, after wound healing, without gastrointestinal tract bleeding and without a history of allergy to cytokines. If overinduced Treg, down-regulated NK and abnormal CD4/
CD8 ratio were not reversed (Treg/lymphocyte $<3 \%$, NK/ lymphocyte $>10 \%, \mathrm{CD} 4 / \mathrm{CD} 8$ ratio $>1$, another course was given.

\section{Radiotherapy}

CyberKnifeand intensity modulated radiation therapy(IMRT) was employed for routine cancer radiotherapy. The total radiation doses were 32.5 to 37.5 GY for CyberKnife, divided into 5 fractions within seven days, and 60 to $70 \mathrm{GY}$ for IMRT, divided into 30-35 fractions, $2 \mathrm{GY}$ per fraction, and 5 fractions per week.

\section{Statistical analysis}

Statistical analyses of data were performed using GraphPad-Prism software (San Diego, CA). Calculations were performed as mean \pm SEM and significance was denoted as ${ }^{*}, \mathrm{p}<0.05 ;{ }^{* *}, \mathrm{p}<0.01$; and ${ }^{* * *}, \mathrm{p}<0.001$.

\section{Author contributions}

The study was designed by Guangxian Liu, Ge Shen and Bing Liu; experiments were performed by Wei Wang, Shiping Song, Yanli Ni, Zuoyao Suo, Dan Li, Lin Zhou, Rimin Hao, Yuewei Zhao, Li Bai and Lili Hou; data was analyzed and interpreted by Guangxian Liu, Ge Shen and Wei Wang; Wei Wang performed statistical analysis; Ge Shen, Shikai Wu, Shiping Song, Xiangying Meng, Dan Li, Rimin Hao and Yaowei Zhao provided patient samples and clinical advice and diagnostic evaluation of tumors and advice; Guangxian Liu, Wei Wang, Ge Shen and Bing Liu wrote the manuscript and all authors reviewed and edited the manuscript.

\section{CONFLICTS OF INTEREST}

All authors have no potential conflicts of interest.

\section{GRANT SUPPORT}

This study was supported by the National Natural Science Foundation (No. 81372251) and study on the Capital clinical Characteristics Foundation (Z151100004015200)

\section{REFERENCES}

1. Okazaki T, Honjo T. PD-1 and PD-1 ligands: from discovery to clinical application. Int Immunol. 2007; 19:813-824.

2. Freeman GJ, Long AJ, Iwai Y, Bourque K, Chernova T, Nishimura H, Fitz LJ, Malenkovich N, Okazaki T, Byrne MC, Horton HF, Fouser L, Carter L, et al. Engagement of the PD-1 immunoinhibitory receptor by a novel B7 family member leads to negative regulation of lymphocyte activation. J Exp Med. 2000; 192:1027-1034. 
3. Latchman Y, Wood CR, Chernova T, Chaudhary D, Borde M, Chernova I, Iwai Y, Long AJ, Brown JA, Nunes R, Greenfield EA, Bourque K, Boussiotis VA, et al. PD-L2 is a second ligand for PD-1 and inhibits T cell activation. Nat Immunol. 2001; 2:261-268.

4. Yamazaki T, Akiba H, Iwai H, Matsuda H, Aoki M, Tanno Y, Shin T, Tsuchiya H, Pardoll DM, Okumura K, Azuma M, Yagita H. Expression of programmed death 1 ligands by murine T cells and APC. J Immunol. 2002; 169:5538-5545.

5. Ishida M, Iwai Y, Tanaka Y, Okazaki T, Freeman GJ, Minato N, Honjo T. Differential expression of PD-L1 and PD-L2, ligands for an inhibitory receptor PD-1, in the cells of lymphohematopoietic tissues. Immunol Lett. 2002; 84:57-62.

6. Keir ME, Butte MJ, Freeman GJ, Sharpe AH. PD-1 and its ligands in tolerance and immunity. Annu Rev Immunol. 2008; 26:677-704.

7. Nishimura H, Minato N, Nakano T, Honjo T. Immunological studies on PD-1 deficient mice: implication of PD-1 as a negative regulator for B cell responses. Int Immunol. 1998; 10:1563-1572.

8. Ferris R. PD-1 targeting in cancer immunotherapy. Cancer. 2013; 119:E1-3.

9. Wolchok JD, Kluger H, Callahan MK, Postow MA, Rizvi NA, Lesokhin AM, Segal NH, Ariyan CE, Gordon RA, Reed K, Burke MM, Caldwell A, Kronenberg SA, et al. Nivolumab plus ipilimumab in advanced melanoma. N Engl J Med. 2013; 369:122-133.

10. Topalian SL, Hodi FS, Brahmer JR, Gettinger SN, Smith DC, McDermott DF, Powderly JD, Carvajal RD, Sosman JA, Atkins MB, Leming PD, Spigel DR, Antonia SJ, et al. Safety, activity, and immune correlates of anti-PD-1 antibody in cancer. N Engl J Med. 2012; 366:2443-2454.

11. Patnaik A, Kang SP, Rasco D, Papadopoulos KP, ElassaissSchaap J, Beeram M, Drengler R, Chen C, Smith L, Espino G, Gergich K, Delgado L, Daud A, et al. Phase I study of pembrolizumab (MK-3475; anti-PD-1 monoclonal antibody) in patients with advanced solid tumors. Clin Cancer Res. 2015; 21:4286-4293.

12. Hamid O, Robert C, Daud A, Hodi FS, Hwu WJ, Kefford R, Wolchok JD, Hersey P, Joseph RW, Weber JS, Dronca R, Gangadhar TC, Patnaik A, et al. Safety and tumor responses with lambrolizumab (anti-PD-1) in melanoma. N Engl J Med. 2013; 369:134-144.

13. Brahmer JR, Tykodi SS, Chow LQ, Hwu WJ, Topalian SL, Hwu P, Drake CG, Camacho LH, Kauh J, Odunsi K, Pitot HC, Hamid O, Bhatia S, et al. Safety and activity of antiPD-L1 antibody in patients with advanced cancer. N Engl J Med. 2012; 366:2455-2465.

14. Robert C, Ribas A, Wolchok JD, Hodi FS, Hamid O, Kefford R, Weber JS, Joshua AM, Hwu WJ, Gangadhar TC, Patnaik A, Dronca R, Zarour H, et al. Anti-programmeddeath-receptor-1 treatment with pembrolizumab in ipilimumab-refractory advanced melanoma: a randomised dose-comparison cohort of a phase 1 trial. Lancet. 2014; 384:1109-1117.

15. Brahmer JR, Drake CG, Wollner I, Powderly JD, Picus J, Sharfman WH, Stankevich E, Pons A, Salay TM, McMiller TL, Gilson MM, Wang C, Selby M, et al. Phase I study of single-agent anti-programmed death-1 (MDX1106) in refractory solid tumors: safety, clinical activity, pharmacodynamics, and immunologic correlates. J Clin Oncol. 2010; 28:3167-3175.

16. Robert C, Schachter J, Long GV, Arance A, Grob JJ, Mortier L, Daud A, Carlino MS, McNeil C, Lotem M, Larkin J, Lorigan P, Neyns B, et al. Pembrolizumab versus Ipilimumab in advanced melanoma. N Engl J Med. 2015; 372:2521-2532.

17. Liu G, Yang W, Guo M, Liu X, Huang N, Li D, Jiang Z, Yang W, Zhang W, Su H, Liu Z, Liu T, Wang D, et al. Effective modulation of CD4(+)CD25 (+high) regulatory $\mathrm{T}$ and NK cells in malignant patients by combination of interferon- $\alpha$ and interleukin-2. Cancer Immunol Immunother. 2012; 61:2357-2366.

18. Wu C, Zhu Y, Jiang J, Zhao J, Zhang XG, Xu N. Immunohistochemical localization of programmed death-1 ligand-1 (PD-L1) in gastric carcinoma and its clinical significance. Actahistochemica. 2006; 108:19-24.

19. Schalper KA, Velcheti V, Carvajal D, Wimberly H, Brown J, Pusztai L, Rimm DL. In situ tumor PD-L1 mRNA expression is associated with increased TILs and better outcome in breast carcinomas. Clin Cancer Res. 2014; 20:2773-2782.

20. Deng L, Liang $H$, Burnette B, Beckett M, Darga T, Weichselbaum RR, Fu YX. Irradiation and anti-PD-L1 treatment synergistically promote antitumor immunity in mice. J Clin Invest. 2014; 124:687-695.

21. Herbst RS, Soria JC, Kowanetz M, Fine GD, Hamid O, Gordon MS, Sosman JA, McDermott DF, Powderly JD, Gettinger SN, Kohrt HE, Horn L, Lawrence DP, et al. Predictive correlates of response to the anti-PD-L1 antibody MPDL3280A in cancer patients. Nature. 2014; 515:563-567.

22. Patel SP, Kurzrock R. PD-L1 expression as a predictive biomarker in cancer immunotherapy. Mol Cancer Ther. 2015; 14:847-856.

23. MacFarlane AW, Jillab M, Plimack ER, Hudes GR, Uzzo RG, Litwin S, Dulaimi E, Al-Saleem T, Campbell KS. PD-1 expression on peripheral blood cells increases with stage in renal cell carcinoma patients and is rapidly reduced after surgical tumor resection. Cancer Immunol Res. 2014; 2:320-331.

24. Waki K, Yamada T, Yoshiyama K, Terazaki Y, Sakamoto S, Matsueda S, Komatsu N, Sugawara S, Takamori S, Itoh K, Yamada A. PD-1 expression on peripheral blood T-cell subsets correlates with prognosis in non-small cell lung cancer. Cancer Sci. 2014; 105:1229-1235. 
25. Bontkes HJ, Ruben JM, Alhan C, Westers TM, Ossenkoppele GJ, van de Loosdrecht AA. Azacitidine differentially affects CD4(pos) T-cell polarization in vitro and in vivo in high risk myelodysplastic syndromes. Leuk Res. 2012; 36:921-930.

26. McDaniel JM, Pinilla-Ibarz J, Epling-Burnette PK. Molecular action of lenalidomide in lymphocytes and hematologic malignancies. Adv Hematol. 2012; 2012:513702.

27. Yang H, Bueso-Ramos C, DiNardo C, Estecio MR, Davanlou M, Geng QR, Fang Z, Nguyen M, Pierce S, Wei Y, Parmar S, Cortes J, Kantarjian H, et al. Expression of PD-L1, PD-L2, PD-1 and CTLA4 in myelodysplastic syndromes is enhanced by treatment with hypomethylating agents. Leukemia. 2014; 28:1280-1288.

28. Ahmadzadeh M, Johnson LA, Heemskerk B, Wunderlich JR, Dudley ME, White DE, Rosenberg SA. Tumor antigenspecific CD8 T cells infiltrating the tumor express high levels of PD-1 and are functionally impaired. Blood. 2009; 114:1537-1544.

29. Thompson RH, Dong H, Lohse CM, Leibovich BC, Blute ML, Cheville JC, Kwon ED. PD-1 is expressed by tumorinfiltrating immune cells and is associated with poor outcome for patients with renal cell carcinoma. Clin Cancer Res. 2007; 13:1757-1761.

30. Muenst S, Schaerli AR, Gao F, Daster S, Trella E, Droeser RA, Muraro MG, Zajac P, Zanetti R, Gillanders WE, Weber WP, Soysal SD. Expression of programmed death ligand 1 (PD-L1) is associated with poor prognosis in human breast cancer. Breast Cancer Res Treat. 2014; 146:15-24.

31. Hamanishi J, Mandai M, Iwasaki M, Okazaki T, Tanaka Y, Yamaguchi K, Higuchi T, Yagi H, Takakura K, Minato N, Honjo T, Fujii S. Programmed cell death 1 ligand 1 and tumor-infiltrating CD8 $+\mathrm{T}$ lymphocytes are prognostic factors of human ovarian cancer. Proc Nat Acad Sci U S A. 2007; 104:3360-3365.

32. Gao Q, Wang XY, Qiu SJ, Yamato I, Sho M, Nakajima Y, Zhou J, Li BZ, Shi YH, Xiao YS, Xu Y, Fan J. Overexpression of PD-L1 significantly associates with tumor aggressiveness and postoperative recurrence in human hepatocellular carcinoma. Clin Cancer Res. 2009; 15:971-979.

33. Hino R, Kabashima K, Kato Y, Yagi H, Nakamura M, Honjo T, Okazaki T, Tokura Y. Tumor cell expression of programmed cell death-1 ligand 1 is a prognostic factor for malignant melanoma. Cancer. 2010; 116:1757-1766.

34. Massi D, Brusa D, Merelli B, Ciano M, Audrito V, Serra S, Buonincontri R, Baroni G, Nassini R, Minocci D, Cattaneo L, Tamborini E, Carobbio A, et al. PD-L1 marks a subset of melanomas with a shorter overall survival and distinct genetic and morphological characteristics. Ann Oncol. 2014; 25:2433-2442.

35. Wherry EJ. T cell exhaustion. Nat Immunol. 2011; $12: 492-499$
36. Hofmeyer KA, Jeon H, Zang X. The PD-1/PD-L1 (B7H1) pathway in chronic infection-induced cytotoxic $T$ lymphocyte exhaustion. J Biomed Biotechnol. 2011; 2011:451694.

37. Youngblood B, Oestreich KJ, Ha SJ, Duraiswamy J, Akondy RS, West EE, Wei Z, Lu P, Austin JW, Riley JL, Boss JM, Ahmed R. Chronic virus infection enforces demethylation of the locus that encodes PD-1 in antigen-specific CD8(+) T cells. Immunity. 2011; 35:400-412.

38. Petrovas C, Casazza JP, Brenchley JM, Price DA, Gostick E, Adams WC, Precopio ML, Schacker T, Roederer M, Douek DC, Koup RA. PD-1 is a regulator of virus-specific CD8+ T cell survival in HIV infection. J Exp Med. 2006; 203:2281-2292.

39. Trautmann L, Janbazian L, Chomont N, Said EA, Gimmig S, Bessette B, Boulassel MR, Delwart E, Sepulveda H, Balderas RS, Routy JP, Haddad EK, Sekaly RP. Upregulation of PD-1 expression on HIV-specific CD8+ $\mathrm{T}$ cells leads to reversible immune dysfunction. Nat Med. 2006; 12:1198-1202.

40. Boettler T, Panther E, Bengsch B, Nazarova N, Spangenberg HC, Blum HE, Thimme R. Expression of the interleukin-7 receptor alpha chain (CD127) on virus-specific CD8+ T cells identifies functionally and phenotypically defined memory $\mathrm{T}$ cells during acute resolving hepatitis $\mathrm{B}$ virus infection. J Virol. 2006; 80:3532-3540.

41. Boni C, Fisicaro P, Valdatta C, Amadei B, Di Vincenzo P, Giuberti T, Laccabue D, Zerbini A, Cavalli A, Missale G, Bertoletti A, Ferrari C. Characterization of hepatitis B virus (HBV)-specific T-cell dysfunction in chronic HBV infection. J Virol. 2007; 81:4215-4225.

42. Radziewicz H, Ibegbu CC, Fernandez ML, Workowski KA, Obideen K, Wehbi M, Hanson HL, Steinberg JP, Masopust D, Wherry EJ, Altman JD, Rouse BT, Freeman GJ, et al. Liver-infiltrating lymphocytes in chronic human hepatitis $\mathrm{C}$ virus infection display an exhausted phenotype with high levels of PD-1 and low levels of CD127 expression. J Virol. 2007; 81:2545-2553.

43. Velu V, Titanji K, Zhu B, Husain S, Pladevega A, Lai L, Vanderford TH, Chennareddi L, Silvestri G, Freeman GJ, Ahmed R, Amara RR. Enhancing SIV-specific immunity in vivo by PD-1 blockade. Nature. 2009; 458:206-210.

44. Quigley M, Pereyra F, Nilsson B, Porichis F, Fonseca C, Eichbaum Q, Julg B, Jesneck JL, Brosnahan K, Imam S, Russell K, Toth I, Piechocka-Trocha A, et al. Transcriptional analysis of HIV-specific CD8+ T cells shows that PD-1 inhibits $\mathrm{T}$ cell function by upregulating BATF. Nat Med. 2010; 16:1147-1151.

45. Day CL, Kaufmann DE, Kiepiela P, Brown JA, Moodley ES, Reddy S, Mackey EW, Miller JD, Leslie AJ, DePierres C, Mncube Z, Duraiswamy J, Zhu B, et al. PD-1 expression on HIV-specific T cells is associated with T-cell exhaustion and disease progression. Nature. 2006; 443:350-354. 
46. Xu J, Escamilla J, Mok S, David J, Priceman S, West B, Bollag G, McBride W, Wu L. CSF1R signaling blockade stanches tumor-infiltrating myeloid cells and improves the efficacy of radiotherapy in prostate cancer. Cancer Res. 2013; 73:2782-2794.

47. Chen FH, Chiang CS, Wang CC, Fu SY, Tsai CS, Jung SM, Wen CJ, Lee CC, Hong JH. Vasculatures in tumors growing from preirradiated tissues: formed by vasculogenesis and resistant to radiation and antiangiogenic therapy. Int $\mathrm{J}$ Radiat Oncol Biol Phys. 2011; 80:1512-1521.

48. Mantovani A, Sica A, Allavena P, Garlanda C, Locati M. Tumor-associated macrophages and the related myeloidderived suppressor cells as a paradigm of the diversity of macrophage activation. Human Immunol. 2009; 70:325-330. 